\title{
Infrastructure maintenance and disaster prevention measures on isolated Islands: the case of the Izu Islands near Tokyo
}

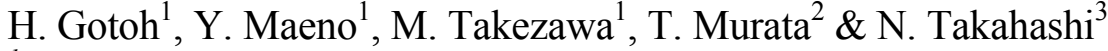 \\ ${ }^{1}$ Nihon University, Japan \\ ${ }^{2}$ Tokyo Metropolitan Government, Japan \\ ${ }^{3}$ Japan Organization of Legend, Culture \& Art, Japan
}

\begin{abstract}
Of the 6,852 islands that make up the Japanese archipelago, 261 are inhabited but there are isolated islands with a total population of approximately 434,000 people scattered over an area of $5,255 \mathrm{~km}^{2}$. In the five years from 2001 to 2005 , the population of these islands decreased by $8.3 \%$ compared to a $0.7 \%$ increase in the national population. The Tokyo Metropolitan Government administers some of these, including the Izu Islands. The Izu group consists of nine separate islands with a total population of 24,645 people spread over $296.56 \mathrm{~km}^{2}$ (2009). The largest island is Izu Oshima (population: 8,346, area: $91.06 \mathrm{~km}^{2}$ ) while the smallest is Toshima (population: 292, area: $4.12 \mathrm{~km}^{2}$ ). The primary industries in the Izu Islands are fisheries, agriculture, and tourism, although the mix varies between islands. Communication between the various islands is by cargopassenger boat, jetfoil and aircraft. While each island has at least one harbor, only five have airports: Izu Oshima, Niijima, Kozujima, Miyakejima and Hachijojima. The smaller islands can be reached by helicopter. Several types of natural disasters, including tsunamis, storm and flood damage, and volcanic eruptions threaten the region. Because of the potential losses that could be suffered in such disasters, the Tokyo metropolitan government has developed disaster prevention and response measures for the Izu Islands. These include supplying residents with hazard maps and evacuation guidance, radios, and simple signs, as well as developing a transport system for emergency supplies. This paper discusses present conditions, and future issues with regard to disaster prevention and response in the Izu island group.
\end{abstract}

Keywords: isolated island, population, living standard, disaster prevention measures. 


\section{Introduction}

The Japanese Archipelago which forms the country of Japan, runs roughly northeast to southwest along the coast of the Eurasian mainland on the northwestern shores of the Pacific Ocean. The archipelago consists of 6,852 islands, but the vast majority of the population lives on the four largest islands (Honshu, Hokkaido, Shikoku and Kyushu). Of the remainder, 261 have been designated as isolated, inhabited islands under the Law for Development of Isolated Islands in Japan [1]. These designated islands cover an area of about $5,255 \mathrm{~km}^{2}(1.39 \%$ of the area of Japan) and are home to 434,000 persons $(0.34 \%$ of the national population). They are generally distant from the main islands and much different from the more densely populated areas with large cities, tall buildings, and suburban towns. The islands are surrounded by natural beauty and blessed with sightseeing and marine resources. They play an important role in land and environmental preservation. Many have potential for development as well as great value because of their pristine condition. Politically, these islands are in an ongoing struggle to balance economic power, stability, and public happiness. The large gaps in income and living standards that exist between the main islands and these isolated areas are a continuing reality affecting that struggle. This paper discusses infrastructure maintenance and disaster prevention and response measures on isolated islands as illustrated in the case of the Izu island region administrated by the Tokyo Metropolitan Government in Japan.

\section{Overview of the Izu Islands}

The Izu Islands are a chain of volcanic ocean islands scattered over several hundred kilometers south of Tokyo, Japan as shown in Fig.1.

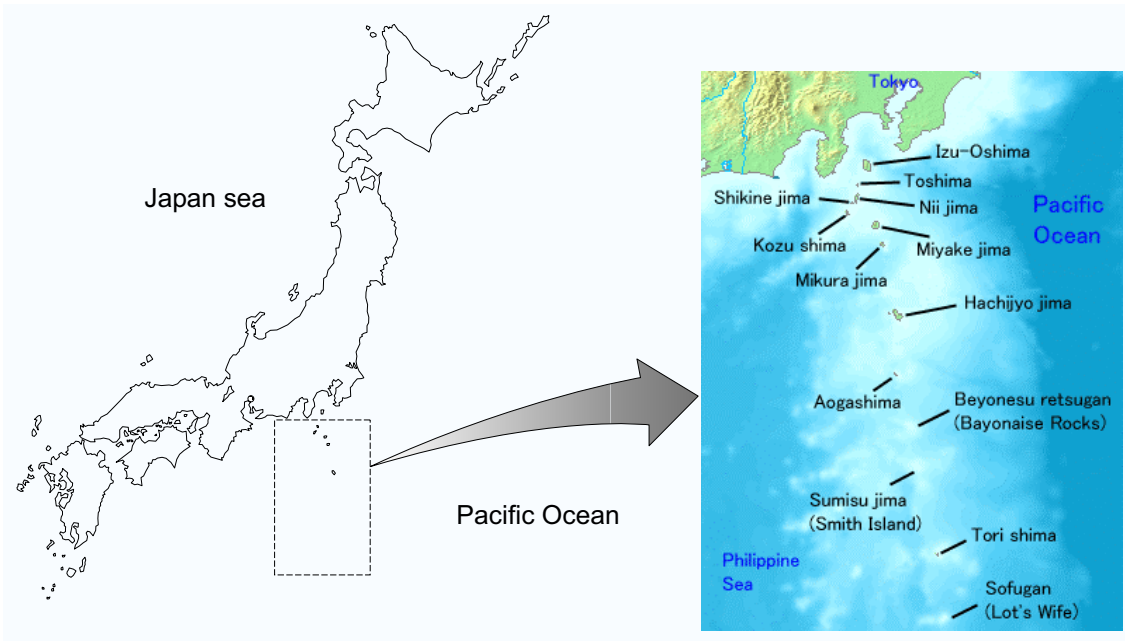

Figure 1: $\quad$ Map of the Izu islands. 
They stretch south and east from the Izu Peninsula of Honshu, Japan, covering an area of about $301.56 \mathrm{~km}^{2}$, which is divided into two towns and six villages. The total population of the group was 24,242 people in 2005 . The largest island is Izu Oshima, usually called simply Oshima. Although traditionally referred to as the "Izu Seven", there are in fact more than a dozen of these islands and islets that lie within the Fuji - Hakone - Izu National Park. Nine are currently inhabited. Of the inhabited islands, Izu Oshima, Toshima, Niijima, Kozujima, Miyakejima, Hachijojima, and Mikurajima are generally thought to comprise the "Izu Seven", but the other two, Shikinejima and Aogashima, are sometimes included. Izu Oshima and Hachijojima each make up one of the towns. Niijima and Shikinejima are joined into one village, and each of the remaining inhabited islands has an individual village. Three subprefectures (Oshima, Miyake and Hachijo), oversee the municipalities as branch offices of the Tokyo metropolitan government. The island closest to Tokyo, Izu Oshima, is $108 \mathrm{~km}$ from the city, while the most distant, Aogashima, is $354 \mathrm{~km}$ away from the Tokyo Metropolitan Office.

Marine sports such as swimming, scuba diving, surfing, and fishing are enjoyed on the islands. Bird watching and trekking are also popular [2]. There are many scenic spots that are crowded with tourists during the summer. Their marine resorts offer fishing, diving and other outdoor activities. Each island has its own unique character and features. Izu Oshima is famous for Mt. Mihara, an active volcano, and its Izu Oshima camellias. Hachijojima has a colorful history as a penal colony, while dolphin watching is offered on Mikurajima. Niijima is known for its many beautiful beaches, Kozujima has amazing white sandy shores, and tourists are gradually returning to Miyakejima since the evacuation orders imposed after a volcanic eruption in 2001 have been lifted. Hachijojima showcases the preservation of its one-of-a-kind culture featuring textiles and traditional performing arts.

Because of their isolation, the islands' flora and fauna and have evolved in their own distinctive ways, producing rare and unique ecosystems. Dolphins and whales can be seen nearby, attracting many tourists, particularly to those islands that lie closer to Honshu. Volcanic activity is frequent in the area. The Eruption of Myojin-sho in 1953 killed 31 people when it destroyed the research vessel Kaiyo Maru No. 5, taking the lives of all those aboard. More recent volcanic activity, including the release of harmful gases, forced the evacuation of Miyakejima in 2000. Five years later, residents were finally allowed to return to the island permanently but were required to carry gas masks in case of future volcanic emissions.

The waters surrounding the Izu Islands and the Ogasawara Islands comprise about $45 \%$ of Japan's marine Exclusive Economic Zone, making the islands vital to the nation's maritime interests.

In 2003, the Tokyo Metropolitan Government proposed a 10-year plan (Isolated Island Promotion Plan) to promote these isolated islands [3]. Its basic policy is the independent development of the Izu Islands, based on the idea that such development will bring about recovery and enhancement of valuable property that is held in common by the entire nation. Under the promotion plan, 
the establishment of island economies based on tourism (sightseeing, in cooperation with agriculture and fisheries) is a high priority. Other important thrusts of the plan are building a synthetic network of communication focusing on visitors, intensive reform of information and communication bases, and establishment of a crisis management system. Plans for facilities needed to support and maintain residents' living environment such as medical institutions, welfare facilities, educational institutions, and cultural properties, are being implemented. The Public Corporation for Promotion of the Izu and Ogasawara Islands was established under the auspices of the Tokyo Metropolitan Government and the communities of islands in 1998 [4]. Its main business is sales promotion of each island's special products and support of heli-commuter services to all of the islands.

Under the 10-year plan, each island's development follows an individualized scheme. Izu Oshima is focusing on promoting sustainable tourism, a cooperative effort among the agriculture, fishery and tourism industries. Toshima is working toward stability and production improvements achieved through attempts at more systematically managing its farming and fisheries. Niijima and Shikinejima hope to attract tourism by offering visitors experiences that showcase the island's natural resources through the cooperation of agriculture, fishery and tourism. They envision a healing program exploiting undersea hot springs to entice visitors throughout the year. Kozujima will promote the image of a natural, healthy island lifestyle that brings visitors relaxation and healing through the cooperation of their tourism and fishing industries. Miyakejima positioned itself with the overall area plan of promoting tourism while actively conserving nature and sensibly managing its fisheries, agriculture, and forestry, etc. Mikurajima planned to activate its economy by drawing visitors to its favorable natural environment. Hachijojima's plan draws tourism by openly sharing its unique history, actively exploiting area resources and synthesizing its agriculture, fisheries, and tourism. Aogashima has activated its economy by strengthening its ability to produce a steady supply of seafood and brand-name marine goods and specialty products.

\section{Population, aging and industrial profiles of the Izu Islands}

The population of the Izu Islands has been dropping steadily, although not as dramatically as the overall drop in Japan's isolated islands. Table.1 shows the population trends for the Izu Islands, the isolated islands as a whole, and the overall Japanese population [5].

Table 2 shows population changes in towns and villages of the Izu Islands between 2000 and 2005. It should be noted that the population of Miyakejima in 2000 was counted before the eruption of Mt. Oyama, and the population and area of Shikinejima are reported together with Niijima [5].

Table 3 shows the age distribution of the population of the Izu Islands in 2005. Again, Shikinejima's data is combined with Niijima's [5].

Primary industries accounted for an average of $12 \%$, secondary industries for $22 \%$ and the tertiary industry for $66 \%$ of the Izu chain's economy in 2005. Agriculture and fisheries, the most prominent primary industries (as of 2005) and 
Table 1: $\quad$ Population changes over time (persons).

\begin{tabular}{|c|c|c|c|}
\hline Year & Izu islands & Isolated islands & Japan \\
\hline 1960 & 38,707 & 923,062 & $94,301,623$ \\
\hline 1970 & 32,539 & 736,712 & $104,665,171$ \\
\hline 1980 & 31,902 & 630,536 & $117,060,396$ \\
\hline 1990 & 30,032 & 546,505 & $123,611,167$ \\
\hline 2000 & 28,756 & 472,312 & $126,925,843$ \\
\hline 2005 & 26,242 & 433,712 & $127,767,994$ \\
\hline
\end{tabular}

Table 2: $\quad$ Population changes in the Izu islands.

\begin{tabular}{|c|c|c|c|}
\hline Town, Village & 2000 (persons) & $2005($ persons $)$ & Area $\left(\mathrm{km}^{2}\right)$ \\
\hline Izu-Oshima & 9,549 & 8,702 & 91.06 \\
\hline Toshima & 297 & 308 & 4.12 \\
\hline Niijima & 3,180 & 3,161 & 27.83 \\
\hline Kozujima & 2,263 & 2,068 & 18.87 \\
\hline Miyakejima & 3,783 & 2,439 & 55.50 \\
\hline Hachijojima & 9,305 & 8,837 & 77.62 \\
\hline Mikurajima & 258 & 292 & 20.58 \\
\hline Aogashima & 193 & 214 & 5.98 \\
\hline
\end{tabular}

Table 3: $\quad$ Age distribution of Izu island population.

\begin{tabular}{|c|c|c|c|}
\hline Town or Village & $0 \sim 14$ years $(\%)$ & $15 \sim 64$ years $(\%)$ & Above 65 years $(\%)$ \\
\hline Izu-Oshima & 12.0 & 59.9 & 28.1 \\
\hline Toshima & 10.6 & 66.7 & 22.8 \\
\hline Niijima & $11 . / 9$ & 56.8 & 31.3 \\
\hline Kozujima & 14.9 & 60.7 & 24.4 \\
\hline Miyakejima & 5.7 & 56.4 & 37.9 \\
\hline Mikurajima & 16.5 & 69.2 & 14.3 \\
\hline Hachijojima & 12.7 & 58.3 & 29.0 \\
\hline Aogashima & 20.2 & 65.2 & 14.6 \\
\hline
\end{tabular}

construction, manufacturing and mining, the largest secondary industries, are declining. On the other hand, tertiary industries, particularly information, transportation, accommodations, real estate and other lifestyle-related work have been increasing every year. Although the levels vary between islands, the main industries of the Izu Islands are fisheries, agriculture, and sightseeing. For example, sightseeing supports Izu Oshima, Niijima, Miyakejima and Mikurajima, agriculture and camellia production are prosperous businesses on Toshima, Kozujima is well known for fishing, and dairies are the basic industry on Aogashima. Hachijojima, a strikingly beautiful island, is popular with surfers, and has many varied scuba diving spots. It is also known for its natural hot springs, hiking, and waterfalls. Table 4 shows the industrial structure of each island in 2005 [5]. 
Table 4: $\quad$ Industrial structure of the Izu islands.

\begin{tabular}{|c|c|c|c|}
\hline Island & $\begin{array}{c}\text { Primary } \\
\text { industries (\%) }\end{array}$ & $\begin{array}{c}\text { Secondary } \\
\text { industries (\%) }\end{array}$ & $\begin{array}{c}\text { Tertiary } \\
\text { industries (\%) }\end{array}$ \\
\hline Izu Oshima & 8 & 16 & 76 \\
\hline Toshima & 21 & 19 & 60 \\
\hline Niijima (and Shikinejima) & 7 & 23 & 68 \\
\hline Kozujima & 19 & 14 & 67 \\
\hline Miyakejima & 6 & 25 & 69 \\
\hline Mikurajima & 2 & 25 & 73 \\
\hline Hachijojima & 19 & 17 & 64 \\
\hline Aogashima & 10 & 36 & 54 \\
\hline
\end{tabular}

\section{Land uses, infrastructure and tourism}

Undeveloped land covers about $86 \%$ of the islands' area, urban districts cover about $8 \%$, half of which is residential use, and farmland constitutes $6 \%$ of the total area. Residential areas are increasing while forested areas are decreasing. In the residential areas, the numbers of individual houses and educational and cultural facilities are increasing. Conversely, agricultural, forestry and fishery facilities, accommodations, playgrounds, and apartments are decreasing every year. The land use percentages for each island are shown in Table 5 [6].

Table 5: $\quad$ Land use percentages.

\begin{tabular}{|c|c|c|c|c|c|c|c|c|c|c|}
\hline & 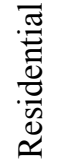 & 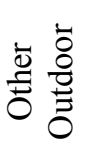 & $\frac{y}{a}$ & 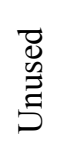 & $\begin{array}{l}\frac{n}{\tilde{J}} \\
0 \\
\tilde{0}\end{array}$ & 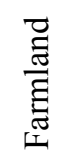 & 离 & $\begin{array}{l}\overrightarrow{\tilde{D}} \\
\stackrel{0}{0} \\
\text { DI }\end{array}$ & $\frac{\theta}{\frac{\theta}{0}}$ & $\frac{\dot{ \pm}}{\stackrel{5}{0}}$ \\
\hline (1) & 5.3 & 0.6 & 0.9 & 0.2 & 2.9 & 4.7 & 0.1 & 64.3 & 21.1 & 14.7 \\
\hline (2) & 3.2 & 0.5 & 0.5 & 0.1 & 3.4 & 2.2 & 0.1 & 67.8 & 22.3 & 9.9 \\
\hline (3) & 4.6 & 3.2 & 1.1 & 0.3 & 3.2 & 2.7 & 0.1 & 72.0 & 12.8 & 15.2 \\
\hline (4) & 2.5 & 0.7 & 0.2 & 0.3 & 4.0 & 10.7 & 0.2 & 54.6 & 26.8 & 18.6 \\
\hline (5) & 2.8 & 0.4 & 0.1 & 0.2 & 2.4 & 4.5 & 0.3 & 77.5 & 11.8 & 10.7 \\
\hline (6) & 0.4 & 0.1 & 0.1 & 0.0 & 0.7 & 1.4 & 0.0 & 84.2 & 13.0 & 2.8 \\
\hline (7) & 5.2 & 0.5 & 0.6 & 0.8 & 4.5 & 12.8 & 0.2 & 71.4 & 4.1 & 24.4 \\
\hline (8) & 2.0 & 0.9 & 0.2 & 0.9 & 2.0 & 10.3 & 0.0 & 57.1 & 26.7 & 16.2 \\
\hline (9) & 3.8 & 0.8 & 0.6 & 0.3 & 2.9 & 6.0 & 0.1 & 71.5 & 14.1 & 14.5 \\
\hline
\end{tabular}

(1) Izu Oshima (2) Toshima (3) Niijima (4) Kozujima (5) Miyakejima (6) Mikurajima (7) Hachijojima (8) Aogashima (9) Isu Islands.

A breakdown of residential land use for each island is shown in Table 6 [6]. Homes occupy about $40 \%$ to $60 \%$ of the residential areas except on Aogashima, where the percentage is less than $30 \%$. 
Table 6: $\quad$ Residential land use (\%).

\begin{tabular}{|c|c|c|c|c|c|}
\hline & Public & Commercial & Housing & Industrial & Farming \\
\hline$(1)$ & 19.1 & 10.8 & 63.7 & 4.1 & 2.3 \\
\hline$(2)$ & 30.1 & 9.9 & 43.5 & 12.7 & 3.8 \\
\hline$(3)$ & 20.5 & 16.3 & 44.3 & 12.2 & 6.6 \\
\hline$(4)$ & 23.1 & 20.2 & 38.2 & 14.8 & 3.7 \\
\hline$(5)$ & 15.6 & 15.5 & 54.5 & 8.6 & 5.8 \\
\hline$(6)$ & 26.2 & 9.2 & 46.8 & 11.5 & 6.2 \\
\hline$(7)$ & 13.5 & 16.2 & 58.2 & 7.1 & 5.1 \\
\hline$(8)$ & 45.0 & 7.5 & 28.2 & 11.4 & 7.8 \\
\hline$(9)$ & 19.9 & 12.4 & 57.9 & 6.5 & 3.3 \\
\hline
\end{tabular}

(1) Izu Oshima (2) Toshima (3) Niijima (4) Kozujima (5) Miyakejima (6) Mikurajima (7) Hachijojima (8) Aogashima (9) Isu Islands.

There are 5 airports, 15 harbors and 19 fishing ports in the Izu Islands. Three commuter airlines fly between Haneda (Tokyo International Airport) and Izu Oshima, Miyakejima, Hachijojima, and three fly from Chofu airport to Izu Oshima, Niijima, Kozujima. These flights take between 30 minutes and an hour. Heli-commuter services fly between Aogashima, Hachijojima, Mikurajima, Miyakejima, Izu Oshima and Toshima. There are ships that sail between Honshu (Tokyo, Yokohama, Atami, and Shimoda) and the Izu Islands. Sailing from Tokyo to the Izu Islands takes from 7 to 10 hours. High-speed jet foils reduce the time between Tokyo and Izu Oshima to about two hours. In 1980, about $1,000,000$ visitors went to the Izu Islands each year, but this number had decreased to about 450,000 visitors by 2008 [7-9].

Transportation on the Izu Islands is by bus, car, motorbike, bicycle, etc. Therefore, roads are important to promoting and cultivating various industries and the to the quality of life of island inhabitants. About $215 \mathrm{~km}$ of paved main roads serve the approximately $300 \mathrm{~km}^{2}$ area of the islands [7-9].

Most of the Izu islands did not modernize quickly because there was no electricity before 1953 , but by 1962 , electricity was available to $98 \%$ of the Izu Island area [7-9].

The following social welfare facilities have been established in the Izu Islands: special homes for the aged (750 residents), home care service centers for the aged of each town and village, comprehensive community support centers for each town and village, nursing homes for the aged, private care and rehabilitation facilities for the physically and mentally challenged, homes for the mentally challenged, home support centers for children, and community welfare centers. There are 18 clinics and 1 hospita1, with 30 doctors in residence on the islands. There are 14 dental offices in the Izu Islands. There are 18 nursery schools serving about 1000 children. There are 15 elementary schools with 1150 schoolchildren, 13 junior high schools with 600 students and 8 high schools serving 750 students [10]. 


\section{Living standards and environmental hygiene}

Standard of living means the level of comfort and wealth that people enjoy. The Asahi Newspaper Company investigated a standard of living measure termed "human energy" (Minryoku [11]). "Human energy" is a composite index constructed using 10 indices of activities and characteristics that correlate with the standard of living. These indices are: Population $\mathrm{I}_{\mathrm{P}}$, number of households $\mathrm{I}_{\mathrm{H}}$, income subjected to taxation $\mathrm{I}_{\mathrm{I}}$, number of employees $\mathrm{I}_{\mathrm{E}}$, value of agriculture products $\mathrm{I}_{\mathrm{A}}$, annual value of shipped industrial products $\mathrm{I}_{\mathrm{S}}$, annual retail sales volume $I_{R}$, deposit accounts $I_{D}$, number of automobiles $I_{C}$, number of television contractors $\mathrm{I}_{\mathrm{T}}$. Table 7 shows this composite index of human energy for each of the Izu islands from 2000-2005. (Shikinejima's data is once again combined with Niijima.)

Table 7: $\quad$ Index of human energy.

\begin{tabular}{|c|c|c|c|c|c|c|}
\hline & 2000 & 2001 & 2002 & 2003 & 2004 & 2005 \\
\hline Oshima & 7.6 & 7.6 & 7.6 & 7.9 & 7.5 & 7.2 \\
\hline Toshima & 0.3 & 0.3 & 0.3 & 0.3 & 0.3 & 0.3 \\
\hline Niijima & 2.6 & 2.5 & 2.4 & 2.5 & 2.7 & 2.7 \\
\hline Kozujima & 1.6 & 1.6 & 1.5 & 1.6 & 1.6 & 1.7 \\
\hline Miyake & 3.2 & 3.2 & 2.5 & 2.5 & 2.2 & 3.3 \\
\hline Mikura & 0.2 & 0.2 & 0.2 & 0.2 & 0.2 & 0.2 \\
\hline Hachijojima & 7.5 & 7.5 & 7.8 & 7.8 & 7.5 & 7.3 \\
\hline Aogashima & 0.2 & 0.2 & 0.2 & 0.2 & 0.2 & 0.2 \\
\hline
\end{tabular}

Table 8 shows changes of $\mathrm{I}_{\mathrm{B}}$ over the six-year period ending in 2005 for each island. The national average is $\mathrm{I}_{\mathrm{B}}=100$.

Table 8: $\quad$ Changes of $\mathrm{I}_{\mathrm{B}}$ over time by island.

\begin{tabular}{|c|r|r|r|r|r|c|}
\hline & 2000 & 2001 & 2002 & 2003 & 2004 & 2005 \\
\hline Oshima & 100.0 & 101.3 & 102.0 & 107.7 & 103.5 & 100.4 \\
\hline Toshima & 150.0 & 150.0 & 129.3 & 109.3 & 124.6 & 124.4 \\
\hline Niijima & 104.0 & 100.0 & 97.1 & 102.5 & 108.4 & 109.3 \\
\hline Kozujima & 88.9 & 88.9 & 85.3 & 90.5 & 94.8 & 99.3 \\
\hline Miyakejima & 106.7 & 106.7 & 84.6 & 87.6 & 81.1 & 126.9 \\
\hline Mikurajima & 100.0 & 100.0 & 90.7 & 95.0 & 91.7 & 101.0 \\
\hline Hachijojima & 101.4 & 101.4 & 106.5 & 107.2 & 104.8 & 102.4 \\
\hline Aogashima & 100.0 & 100.0 & 126.3 & 113.1 & 116.7 & 115.7 \\
\hline
\end{tabular}

Individual indices are calculated by scaling parameters to the national average. For example, the population index $I_{P}$ is calculated as follows:

$$
\mathrm{I}_{\mathrm{P}}=\{(\text { area population }) /(\text { national population })\} \times 100000
$$

where 100000 is the national index. 
The annual value of shipped industrial products $\mathrm{I}_{\mathrm{S}}$ and the annual selling cost of retailer $\mathrm{I}_{R}$ are given weights of 22 and 47 respectively compared to the value of agricultural production. The index of human energy I, is calculated as

$$
\mathrm{I}=\left\{\mathrm{I}_{\mathrm{P}}+\mathrm{I}_{\mathrm{H}}+\mathrm{I}_{\mathrm{I}}+\mathrm{I}_{\mathrm{E}}+\left(\mathrm{I}_{\mathrm{A}}+22 \mathrm{I}_{\mathrm{S}}+47 \mathrm{I}_{\mathrm{R}}\right) / 70+\mathrm{I}_{\mathrm{D}}+\mathrm{I}_{\mathrm{C}}+\mathrm{I}_{\mathrm{T}}\right\} / 8
$$

A per capita index $I_{B}$ of human energy is then calculated.

$$
\mathrm{I}_{\mathrm{B}}=\mathrm{I} / \mathrm{I}_{\mathrm{P}}
$$

Each island except for Kozujima has indices of 100 or over in $2000 \sim 2005$. For comparison, the per capita index for the center of Tokyo is about 300, while values for other isolated islands range from 80 to 95 .

There are 40 barbershops, 49 beauty salons, 13 laundries, and 31 public bathhouses on the islands.

Water is in short supply on each island. Island inhabitants were long dependent on stored rainwater, but since 1953, small-scale water works have been built and expanded. Over $99 \%$ of the islands' area has water service as of 2008. However, the water rates in the Izu islands are higher than those on the mainland because of construction costs and public loans taken out to build these small-scale water works.

Until the late 1960s garbage was collected then dumped at streams or on the coast, or incinerated in individual gardens and yards. Refuse incinerators were set up in each town and village in the period from 1961 to 1975. Garbage is now separated by type and collected by designated carriers. Human waste is pumped out then treated at sewage disposal facilities [7-9].

\section{Disaster prevention and response measures}

In order to respond promptly and consistently to emergencies, the Tokyo Metropolitan Government created a special association to develop a crisis management system to gather and analyze information and create strategies for dealing with disasters. The Tokyo Metropolitan Government established a disaster prevention system, centered at its Disaster Countermeasure Headquarters. The system coordinates with the national government, municipalities, and other agencies based on information from the Disaster Prevention Center.

During a catastrophic disaster, effective initial responses will minimize the damage incurred. The Tokyo Metropolitan Government has established several measures to insure appropriate initial response to disasters. At night and during holidays, the center has an after-hours communication office and accommodations for disaster management staff. An emergency government wireless system has also been installed to secure means of collecting and delivering information from seismometer networks, supervisory video cameras, and a disaster information system. In the event of a catastrophic disaster, the Tokyo Metropolitan Government will set up a "Tokyo Metropolitan Government Disaster Countermeasure Headquarters" (headed by the governor of Tokyo) to 
discuss various measures including information gathering, fire fighting, firstaid/rescue, etc. and implement necessary responses [12].

The Izu Islands are in the path of typhoons every year. Therefore, each one experiences strong winds or heavy rain every year. They also experience frequent earthquakes. The islands are part of an area that the Japanese government has determined that disaster measures for earthquakes are a high priority.

The Tokyo Metropolitan Government issued a report predicting the level of inundation due to tsunamis in the Izu Islands as estimated by current research in 2004 [3] and published its planned disaster prevention and response measures for the Izu Islands for flood damage and earthquakes in 2006 [12]. Each of the Izu Islands endeavors to stockpile the necessary preserved foods, clothing, carpets, and other goods called for by the Tokyo Metropolitan Government's disaster ordinances. Plans for emergency operation of helicopters are in place and emergency services have been improved for the safety of island inhabitants.

An emergency radio broadcast system was established in 1970, and the Tokyo Metropolitan Government disaster information system was instituted in 1991. Consequently, it is possible to transmit disaster information between the Tokyo Metropolitan Government disaster center and each of Izu Islands. The communication equipment necessary for these services was refurbished in 2008.

Other disaster prevention measures deal with volcanic eruptions. Izu Oshima is famous for Mt. Mihara, which last erupted in 1986. Mt. Oyama on Miyakejima has also erupted several times in recent history. A lava flow in 1940 killed 11 people, and other eruptions occurred in 1962 and 1983. On July 14, 2000, Mt. Oyama began another series of eruptions, and by September, the island was completely evacuated. After a four-year period of volcanic emissions, residents were allowed to return permanently on February 1, 2005. Since the eruption, there has been a constant flow of sulfuric gas coming from Mt. Oyama.

After the eruption in 2000 disaster information numbers were supplied to residents, and the $6 \mathrm{mG}$ radio system serving the Izu Islands was serviced in 2009 to insure its proper operation in emergencies [7-9].

Harbors in the Izu Islands play a major role as evacuation sites, transportation bases for evacuation of the injured, and staging areas for incoming relief efforts. Airports and heli-ports serve similar roles in information gathering and dissemination, transportation of injured earthquake victims, and transport of relief supplies and workers. As each island is different, it is necessary to pay particular attention to the individual needs of each island as disaster prevention training is conducted. In the future, harbors must be maintained so as to allow ferryboats to berth in emergencies [13].

\section{Conclusions}

First, there is a practical limit to the population of each island in the Izu chain. The population of Izu islands is well known, and even though the standard of living on the islands has been increasing yearly as measured by the human energy index, the islands' population is declining as shown in Tables 1, 7 and 8. 
Thus there is a limit to the number of people who may need to be evacuated from the Izu Islands in an emergency such as a volcanic eruption or a Tsunami.

Second, maintaining the infrastructure necessary in times of emergency is important. This requires a long-term investment to protect the Izu Islands. To address the needs of the islands, the Tokyo Metropolitan Government has formulated various courses of action such as the 10-year Plan for the Promotion of Isolated islands in Tokyo (2003-2012). These plans stress cooperation between agriculture, fisheries, and tourism, development of a total transportation network, institution of information dispatch systems and disaster prevention.

Finally, disaster prevention measures need to be communicated to all island inhabitants. The improvement of the following facilities and equipment is being promoted so that disaster management activities can be conducted quickly and smoothly: observation equipment such as meteorological satellites, weather observation radar and seismometers; materials and machinery required for emergency response such as firefighting equipment, water tanks and power generators; systems for liaising and communicating emergency information such as telecommunications or broadcasting facilities; transportation vehicles such as helicopters, ships and automobiles; facilities for evacuation and headquarters for disaster countermeasures. In addition, projects such as fireproofing buildings, providing evacuation routes, designating areas and facilities as disaster preparation bases have been carried out.

\section{References}

[1] http://law.e-gov.go.jp/htm|data//s28/s28HO072.html, Law for Development of Isolated Islands, Japanese Government, 2002

[2] http://en.wikipedia.org/wiki/Izu-islands, Izu islands, Wikipedia.

[3] Tokyo Metropolitan Government, The Promotion Plan for Isolated Islands in Tokyo, 2004

[4] Tokyo Metropolitan Government and Island Communications Foundation, Public Cooperation for Promotion of Izu and Ogasawara Islands, 1998.

[5] Japanese Government, Population Census, 2006

[6] Tokyo Metropolitan Government, Land use in Tokyo, 2009

[7] Tokyo Metropolitan Government, Outline of Oshima subprefecture, 2009

[8] Tokyo Metropolitan Government, Outline of Miyake subprefecture, 2009

[9] Tokyo Metropolitan Government, Outline of Hachijo subprefecture, 2009

[10] Health Centers on Tokyo's Isolated Islands, Outline of Social Works, Tokyo Metropolitan Government, 2008

[11] Asahi newspaper, Minryoku (2000 2005), Asahi Newspaper Office, 2000 $\sim 2005$

[12] Tokyo Metropolitan Government, TMG's Disaster Prevention Information, http://www.bousai.metro.tpkyo.jp/english/e-tmg/system.htr

[13] Tokyo Metropolitan Government, Business Plan for The Tokyo Metropolitan Government's Earthquake Disaster Measures, 2004. 